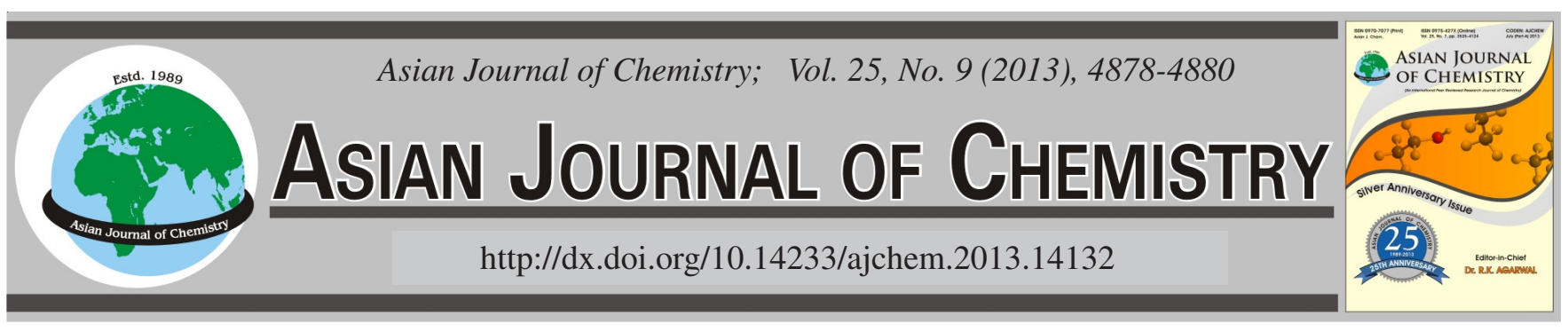

\title{
Effect of Naphthyridine-Like Structure in Polyacrylonitrile Stabilized Fibers on the Modulus of Carbon Fibers
}

\author{
Chun Zhao, Aujun Gao*, Kai Wang, Lingeiang Kong and Lianghua Xu
}

National Carbon Fiber Engineering Research Center, Beijing University of Chemical Technology, Beijing 100029, P.R. China

*Corresponding author: Tel/Fax: +86 10 64435913; E-mail: gaoij@yahoo.com.cn

\section{INTRODUCTION}

Polyacrylonitrile (PAN)-based carbon fibers, which are formed with polycrystalline graphite and amorphous carbon, are most widely used as reinforcement for composites. The performance of carbon fibers depends on their structure. General carbonization process with high temeparature is the way to improve the modulus of carbon fibers. The thermal stabilization of polyacrylonitrile fibers is an important process before carbonization in the fabrication of high performance carbon fibers, during which polyacrylonitrile fibers are converted to infusible, nonflammable fibers by heating to 180 $300{ }^{\circ} \mathrm{C}$ for $\mathrm{ca} .1 \mathrm{~h}$. During this process, complex chemical reactions occur, which accompanied with significant enthalpy changes. The chemical reaction mechanism during the thermal stabilization of polyacrylonitrile has been investigated by many researchers ${ }^{1-17}$. The structures formed in the stabilization process can influence the structure of the resulting carbon fibers and also affect the modulus.

In this study, the characteristic structure of polyacrylonitrile stabilized fibers was investigated in depth, in relation to the modulus of carbon fibers.

\section{EXPERIMENTAL}

Three kinds of polyacrylonitrile fibers with different diameters were used. Their diameters were 6.0, 7.0 and 8.5 $\mu \mathrm{m}$, respectively. The stabilized temperatures were set at 200 , $218,223,237,251$ and $264{ }^{\circ} \mathrm{C}$ and at each temperature the heating time was $10 \mathrm{~min}$. Then the stabilized fiber was carbonized at $350,450,680,900$ and $1350{ }^{\circ} \mathrm{C}$ to get carbon fibers, at each temperature the heating time was $1 \mathrm{~min}$.

The cross-polarization/magic angle spinning (CP/MAS) solid state ${ }^{13} \mathrm{C}$ NMR spectra for the stabilized fiber samples were measured on a Bruker AV-300 NMR spectrometer. A resonance frequency of $73.5 \mathrm{MHz}$, a CP contact time of $3 \mathrm{~ms}$ and a delay time of $5 \mathrm{~s}$ were set as the operating parameters. The probe size for the CP/MAS was $4 \mathrm{~mm}$ and a rotation speed of $12 \mathrm{KHz}$ was employed. For a good signal-to-noise ratio, 300-3175 scans were required. TMS was used as the internal reference to determine the correct chemical shifts.

Crystallite size of carbon fiber was determined using a Philips X'Pert PRO MDP diffractometer (operated at $40 \mathrm{kV}$ and $40 \mathrm{~mA}$ ) with Ni-filtered $\mathrm{CuK}_{\alpha}$ radiation. Data were collected over the $2 \theta$ range $10-60^{\circ}$ at $1^{\circ} \min ^{-1}$ scan rate. The apparent crystallite size was calculated from the Scherrer equation: La $=\mathrm{K} \lambda / \mathrm{B} \cos \theta$. Where $\theta$ is the diffraction peak position of the (100) plane, $\lambda=0.15406 \mathrm{~nm}$ is the wavelength of the $\mathrm{X}$-rays, $\mathrm{B}$ is the FWHM in radians of the peak and $\mathrm{K}$ is the Scherer geometric or shape factor. The shape factor $\mathrm{K}$ is 1.84 for La.

Raman spectroscopy of carbon fiber was carried out using a Renishaw RM2000 Raman spectrometer (Renishaw Plc, UK) attached to an Olympus optical microscope and a He-Ne laser with wavelength $514.5 \mathrm{~nm}$. The $20 \times$ objective lens of the microscope was used both to focus the laser beam on the specimen and to collect the scattered radiation. The laser beam was polarized parallel to the fiber axis and focused to give a $5 \mu \mathrm{m}$ 
diameter spot on the fiber surface. Typical exposure times for carbon fibers ranged from 20-30 s. There are two characteristic peaks, the D peak near $c a .1320 \mathrm{~cm}^{-1}$ indicates a disordered structure and the $\mathrm{G}$ peak near $1575 \mathrm{~cm}^{-1}$ indicates a graphite structure. $\mathrm{R}=\mathrm{ID} / \mathrm{IG}$ (ID and IG represent integral intensities of the $\mathrm{D}$ and $\mathrm{G}$ peaks, respectively) was used to indicate the degree of graphitization of fibers. Smaller R values mean a higher degree of graphitization of the carbon fibers.

Modulus test for each fiber multifilament was carried out using a universal testing machine (AG-1S, Shimadzu, Japan), with a load cell of $1 \mathrm{kN}$ at a crosshead speed of $10 \mathrm{~mm} / \mathrm{min}$, according to GB/T 3362-1982.

\section{RESULTS AND DISCUSSION}

Typical solid-state ${ }^{13} \mathrm{C}$ NMR spectra of stabilized polyacrylonitrile fiber: Fig. 1 shows the typical solid state ${ }^{13} \mathrm{C}$ NMR CP/MAS spectra of stabilized fiber samples. The peak at 30 ppm ( $\mathrm{a}$ and $\mathrm{b}$ ) is due to $\mathrm{CH}$ and $\mathrm{CH}_{2}$ carbon atoms. The peak at 116 ppm (c) is due to $\mathrm{C}=\mathrm{C}$ carbon atoms and is identifiable as it is not substituted with hydrogen atoms. The peak at 122 ppm (d) is due to the $-\mathrm{C}=\mathrm{N}$ carbon atoms and the peak at 139 ppm (e) is due to $\mathrm{C}=\mathrm{C}$ carbon atoms where at least one of the substituents is a hydrogen atom. The peak at $153 \mathrm{ppm}$ (f) is due to $\mathrm{C}=\mathrm{N}$ carbon atoms which have formed from $-\mathrm{C}=\mathrm{N}$ units (d). Finally the peaks at $177 \mathrm{ppm}(\mathrm{g})$ and above are due to the carbon atoms of $\mathrm{C}=\mathrm{O}$ units $^{18-20}$. The appearance of peak $\mathrm{c}$, e $\mathrm{f}$ indicates that cyclization reactions take place and result in unsaturated carbon structures $\left(s p^{2}\right)$ in the stabilization process.

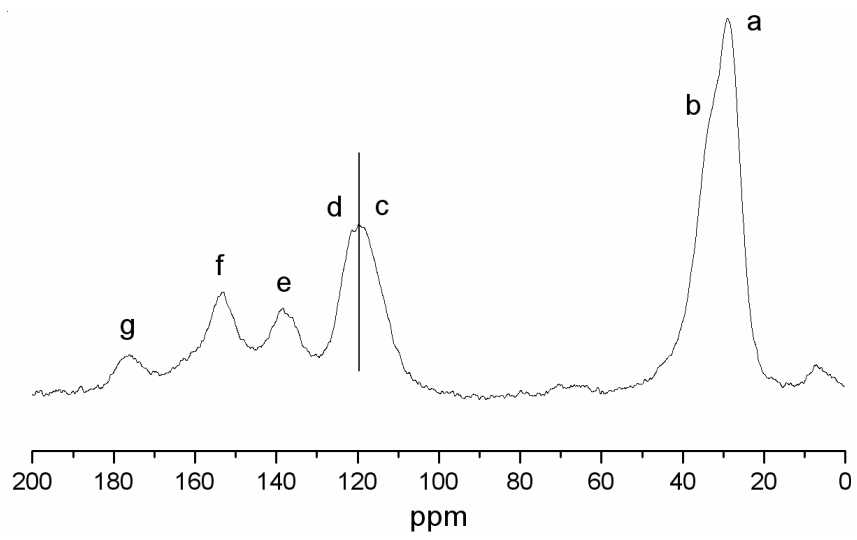

Fig. 1. Solid-state ${ }^{13} \mathrm{C}$ NMR spectra of a stabilized polyacrylonitrile fiber

According to the resonance peak analysis, it can be identified that the structure as shown in Fig. 2 is the main structure in the stabilized fibers. It was named naphthyridine-like structure, which can be considered as the characteristic structure of polyacrylonitrile stabilized fibers.

Effect of stabilized time and diameter on naphthyridinelike structure: Fig. 3a shows ${ }^{13} \mathrm{C}$ NMR spectra of polyacrylonitrile stabilized fibers with different heating time with longer time the combined peak stands for $\mathrm{C}=\mathrm{C}(116 \mathrm{ppm})$ and $\mathrm{C}=\mathrm{N}$ (122 ppm) moves to low field, which means the account of $\mathrm{C}=\mathrm{C}(116 \mathrm{ppm})$ increased and $\mathrm{C}=\mathrm{N}(122 \mathrm{ppm})$ decreased. As time increasing, the peak at 116, 122 and 153 ppm becomes more intense and the peak at $122 \mathrm{ppm}$ is weaker. As shown in Table-1, with stabilized time increased, the content of the groups which resonance peaks at 116, 122 and 153 ppm became<smiles></smiles>

Fig. 2. Naphthyridine-like structure
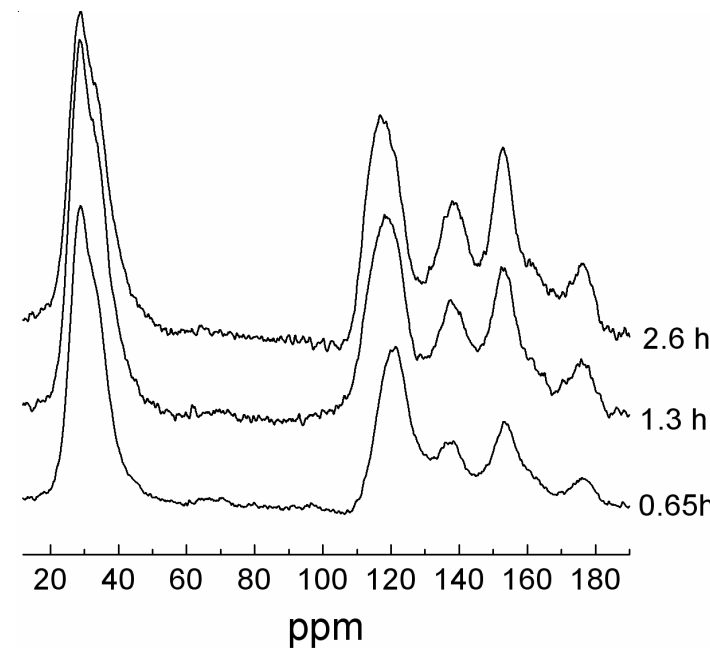

(a)

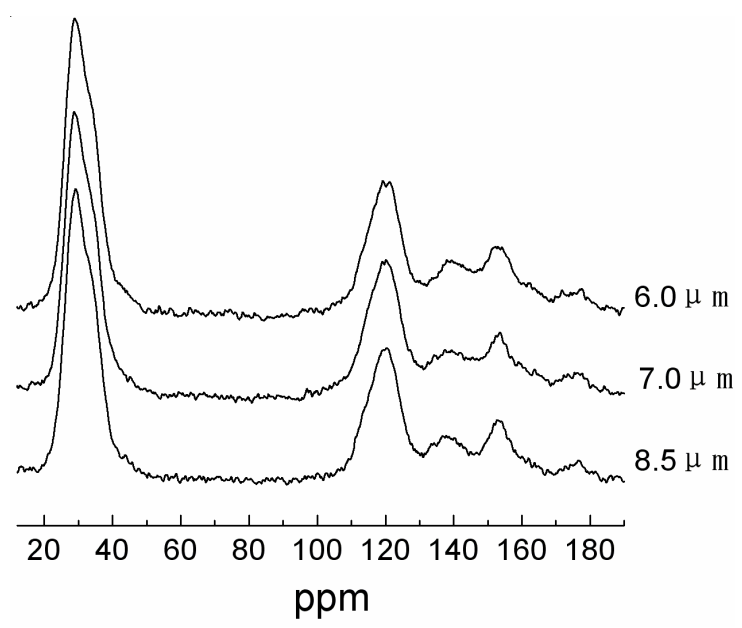

(b)

Fig. 3. ${ }^{13} \mathrm{C}$ NMR spectra of polyacrylonitrile stabilized fibers (a) different stabilization times (b) different diameters

TABLE-1

CONTENT OF GROUPS IN STABILIZED PAN FIBER WITH DIFFERENT TIMES BY SOLID-STATE ${ }^{13} \mathrm{C}$ NMR SPECTRUM

\begin{tabular}{ccccc}
\hline $\begin{array}{c}\text { Time } \\
(\mathrm{h})\end{array}$ & $\begin{array}{c}\mathrm{C}=\mathrm{C} \\
(116 \mathrm{ppm})\end{array}$ & $\begin{array}{c}\mathrm{C} \equiv \mathrm{N} \\
(122 \mathrm{ppm})\end{array}$ & $\begin{array}{c}\mathrm{C}=\mathrm{C} \\
(139 \mathrm{ppm})\end{array}$ & $\begin{array}{c}\mathrm{C}=\mathrm{N} \\
(153 \mathrm{ppm})\end{array}$ \\
\hline 0.65 & 0.063 & 0.156 & 0.084 & 0.127 \\
1.3 & 0.080 & 0.137 & 0.096 & 0.153 \\
2.6 & 0.094 & 0.114 & 0.117 & 0.174 \\
\hline
\end{tabular}

more and more and the peaks at 122 ppm was less and less. This means the amount of naphthyridine-like structure increased with the increasing stabilization time.

From Fig. 3(b) and Table-2, it can be known that decreasing the diameter also improved conversion of $-\mathrm{C}=\mathrm{N}$ to- $\mathrm{C}=\mathrm{N}$ - and achieved more naphthyridine-like structures.

Effect of stabilized time and diameter on modulus of carbon fibers: The modulus, $\mathrm{R}$ and $\mathrm{La}$ of carbon fibers from 


\begin{tabular}{ccccc}
\hline \multicolumn{5}{c}{ TABLE-2 } \\
\multicolumn{5}{c}{ CONTENT OF GROUPS IN STABILIZED PAN } \\
& $\begin{array}{c}\text { FIBER WITH DIFFERENT DIAMETERS BY } \\
\text { SOLID-STATE }{ }^{13} \mathrm{C} \text { NMR SPECTRUM }\end{array}$ \\
\hline $\begin{array}{c}\text { Diameter } \\
(\mu \mathrm{m})\end{array}$ & $\begin{array}{c}\mathrm{C}=\mathrm{C} \\
(116 \mathrm{ppm})\end{array}$ & $\begin{array}{c}\mathrm{C} \equiv \mathrm{N} \\
(122 \mathrm{ppm})\end{array}$ & $\begin{array}{c}\mathrm{C}=\mathrm{C} \\
(139 \mathrm{ppm})\end{array}$ & $\begin{array}{c}\mathrm{C}=\mathrm{N} \\
(153 \mathrm{ppm})\end{array}$ \\
\hline 6.0 & 0.087 & 0.133 & 0.070 & 0.127 \\
7.0 & 0.074 & 0.155 & 0.068 & 0.107 \\
8.5 & 0.065 & 0.173 & 0.063 & 0.095 \\
\hline
\end{tabular}

polyacrylonitrile fibers stabilized with different times are listed in Table-3. Modulus of carbon fibers increases with increasing stabilized time. The $\mathrm{R}$ of the carbon fibers decreased as the heating time increased, meaning the longer time the stabilization time, the higher the graphitization of the carbon fiber. The crystallite size also increases with the prolonging time. High degree of graphitization achieves high modulus.

TABLE-3

PARAMETERS OF CARBON FIBERS FROM POLYACRYLONITRILE FIBERS WITH VARIOUS STABILIZED TIMES

$\begin{array}{cccc}\mathrm{t}(\mathrm{h}) & \text { Modulus (Mpa) } & \mathrm{R} & \mathrm{La}(\mathrm{nm}) \\ 0.65 & 241 & 0.842 & 2.790 \\ 1.30 & 257 & 0.822 & 2.800 \\ 2.60 & 275 & 0.769 & 2.908\end{array}$

Table- 4 shows the modulus, $\mathrm{R}$ and La of carbon fibers from polyacrylonitrile fibers with different diameters. Modulus increases with the diameter decreases. And as the diameter decreased, $\mathrm{R}$ decreased and La increases. This is because reducing the diameter of the fiber improves mass and heat transfer and the polycondensation and cross-linking processes in the fiber increased and is benefit to the growth of the graphite layers. And then the modulus improved because of the high degree of graphitization and larger crystallite size.

\begin{tabular}{cccc}
\hline \multicolumn{4}{c}{ TABLE-4 } \\
PARAMETERS OF CARBON FIBERS PRODUCED \\
FROM POLYACRYLONITRILE FIBERS \\
WITH DIFFERENT DIAMETERS \\
\hline Diameter $(\mu \mathrm{m})$ & Modulus $(\mathrm{Mpa})$ & $\mathrm{R}$ & $\mathrm{La}(\mathrm{nm})$ \\
\hline 6.0 & 236 & 0.846 & 2.618 \\
7.0 & 267 & 0.839 & 2.621 \\
8.5 & 289 & 0.793 & 2.655 \\
\hline
\end{tabular}

According to the above analysis, the effect mechanism for naphthyridine-like structure to modulus can be proposed. The cyclization reaction occurs and results in forming naphthyridine-like structure. Small naphthyridine-like structures react again with each other to form larger naphthyridine-like structures. The heteroatoms like $\mathrm{N}$ escape in carbonization process and form graphite layers, which is benefit to the modulus of carbon fiber. The more the naphthyridine-like structures formed in the stabilization process, the larger and more the graphite crystallite is and the higher the modulus is.

\section{Conclusion}

The structural evolution during the thermal stabilization of polyacrylonitrile fibers was studied using solid state ${ }^{13} \mathrm{C}$ nuclear magnetic resonance. The modulus and structure of the resulting carbon fiber were also investigated. Naphthyridinelike structure, that called characteristics structure in the stabilization process, can influence the modulus of carbon fiber. The more the naphthyriding-like structure is, the higher the modulus is. The amount of naphthyriding-like structure increased with increasing time and small diameter achieved more naphthyridinglike structure at the same stabilization time and temperature. So prolonging the stabilization time and decreasing the diameter of polyacrylonitrile fibers can achieve high modulus carbon fibers.

\section{ACKNOWLEDGEMENTS}

Financial support from the National Basic Research Program of China (2011CB605602) is gratefully acknowledged.

\section{REFERENCES}

1. M.K. Jain and A.S. Abhiraman, J. Mater. Sci., 22, 278 (1987).

2. S.C. Martin, J.J. Liggat and C.E. Snape, Polym. Degrad. Stab., 74, 407 (2001).

3. E. Fitzer and D.J. Müller, Carbon, 13, 63 (1975).

4. W. Watt and W. Johnson, Nature, 257, 210 (1975).

5. M.M. Coleman, G.T. Sivy, P.C. Painter, R.W. Snyder and B. Gordon, Carbon, 21, 255 (1983).

6. I. Shimada, T. Takahagi, K. Morita and A. Ishitani, J. Polym. Sci., Polym. Chem., 24, 1989 (1986).

7. T.J. Xue, M.A. Mckinney and C.A. Wilkie, Polym. Degrad. Stab., 58, 193 (1997)

8. H. Kakida and K. Tashiro, Polym. J., 30, 463 (1998).

9. P. Bajaj, T.V. Sreekumar and K. Sen, Polymer, 42, 1707 (2001).

10. D.B. Jin, Y. Huang, X.L. Liu and Y.Z. Yu, J. Mater. Sci., 39, 3365 (2004).

11. M.S.A. Rahaman, A.F. Ismail and A. Mustafa, Polym. Degrad. Stab., 92, 1421 (2007).

12. D.X. He, C.G. Wang, Y.J. Bai, N. Lun, B. Zhu and Y.X. Wang, J. Mater. Sci., 42, 7402 (2007).

13. Q. OuYang, C. Lu, H.J. Wang and K.X. Li, Polym. Degrad. Stab., 93, 1415 (2008).

14. Q. Ouyang, L. Cheng, H.J. Wang and K.X. Li, J. Therm. Anal. Calorim., 94, 85 (2008).

15. Y.P. Hou, T.Q. Sun, H.J. Wang and D. Wu, J. Appl. Polym. Sci., 114, 3668 (2009).

16. C.S. Cui, L.N. Yu and C.G. Wang, J. Appl. Polym. Sci., 117, 1596 (2010).

17. S.J. Xiao, H.H. Lv, Y.J. Tong, L.H. Xu and B.H. Chen, J. Appl. Polym. Sci., 122, 480 (2011).

18. H.S. Fochler, J.R. Mooney, L.E. Ball, R.D. Boyer and J.G. Grasselli, Spectrochim. Acta A, 41, 271 (1985).

19. T. Usami, T. Itoh, H. Ohtani and S. Tsuge, Macromolecules, 23, 2460 (1990).

20. S.C. Martin, J.J. Liggat and C.E. Snape, Polym. Degrad. Stab., 74, 407 (2001). 